\title{
РІВНЯННЯ СТАНУ МАГНІТНОЇ РІДИННОЇ СИСТЕМИ НА ОСНОВІ ВОДИ ТА МАГНЕТИТУ, СТАБІЛІЗОВАНОЇ ЛАУРИНОВОЮ КИСЛОТОЮ
}

\author{
Л.А. БУЛАВІН, К.О. МОРОЗ, С.П. НЕДЯК, В.І. ПЕТРЕНКО
}

УДК 536.7; 539.6; 544.27

(c) 2012

Київський національний університет ім. Тараса Шевченка

(Вул. Володимирсъка, 64, 01601 Kü̈; e-mail:

morozko@univ. kiev. ua, bulavin@univ. kiev. ua, spnedyak@mail. ru)

\begin{abstract}
У даній статті представлено результати дослідження термодинамічних властивостей магнітної рідинної системи на основі води та магнетиту, стабілізованої подвійним шаром лауринової кислоти, що нанесений на магнетит. Значення термодинамічних властивостей досліджуваної системи розраховано на основі експериментально виміряних для різних тисків і температур значень густини магнітної рідинної системи. Побудовано, проаналізовано та зіставлено з аналогічними даними для води баричні та температурні залежності густини, ізобаричного коефіцієнта теплового розширення, ізотермічного приросту ентропії досліджуваного ферофлюїду. Отримані експериментальні $P-V-T$ дані магнітної рідинної системи описано за допомогою напівемпіричного рівняння стану Тейта-Таммана. Проаналізовано та зіставлено з аналогічними даними для води температурні залежності параметрів побудованого рівняння стану.
\end{abstract}

\section{1. Вступ}

Магнітні рідинні системи є унікальними рідинними системами, які зберігають властивість плинності речовини та реагують на прикладене магнітне поле [13]. Дослідження термодинамічних властивостей таких систем та їх молекулярної будови має як фундаментальне, так і прикладне значення. Згідно зі статистичною теорією рідин та рідинних систем, їх фізичні властивості залежать від молекулярної будови, а та, в свою чергу, чутлива до густини системи. Змінюючи тиск у системі, можна змінювати густину системи та їі молекулярну будову [4]. Тому дослідження впливу високих тисків на фізичні властивості магнітних рідинних систем дозволяе з'ясувати деталі зв'язку між фізичними властивостями магнітних рідинних систем та їх молекулярною будовою. Слід зазначити, що магнітні рідинні системи широко застосовуються у техніці та є перспективними для використання у медицині. Розмір частинок магнітної речовини у рідинній системі ( 10 нм) визначає їх однодоменний стан i робить такі системи чутливими до зовнішнього магнітного поля. Взаємодію між частинками у магні- тній рідинній системі можна регулювати за допомогою зміни фізичних властивостей стабілізуючих шарів, які покривають магнітну частинку. Стабілізуючі шари з поверхнево-активних речовин у магнітній рідинній системі можуть забезпечувати інтерфейс для функціональних молекул і комплексів [4-6]. На сьогодні вже існують магнітні рідинні системи з широким спектром фізичних властивостей, які створені на основі води, вуглеводнів, рідких металів [7-12].

Метою даної роботи є експериментальне дослідження термодинамічних властивостей магнітної рідинної системи на основі води та магнетиту, що стабілізована подвійним шаром лауринової кислоти навколо магнетиту. Як магнітний матеріал у досліджуваній магнітній рідинній системі використовували наночастинки магнетиту $\mathrm{Fe}_{3} \mathrm{O}_{4}$. Об'ємна частка магнетиту у досліджуваному ферофлюїді становила 2,4\%.

\section{2. Методика експерименту}

$P-V-T$ дослідження системи вода-магнетит-лауринова кислота виконано за допомогою методу сільфонного п'єзометра [4] з диференційним трансформаторним датчиком лінійних переміщень. $P-V-T$ дані досліджуваної рідинної магнітної системи отримано за допомогою установки, до складу якої входять системи створення та вимірювання високого тиску, система термостатування та вимірювання температури, робоча камера та реєструюча частина. Блок-схему установки подано на рис. 1. Установка дозволяє отримати $P-V-T$ дані рідинної системи в інтервалі тисків 0,1-101,3 МПа та температур 290-330 K.

Дані про густину системи на лінії рівноваги рідинапара отримано за допомогою пікнометричного методу. Вимірювання густини пікнометром полягало у визначенні маси речовини в об'ємі, значення якого є відомим. Похибка вимірювання густини становила $\pm 0,04 \%$. 


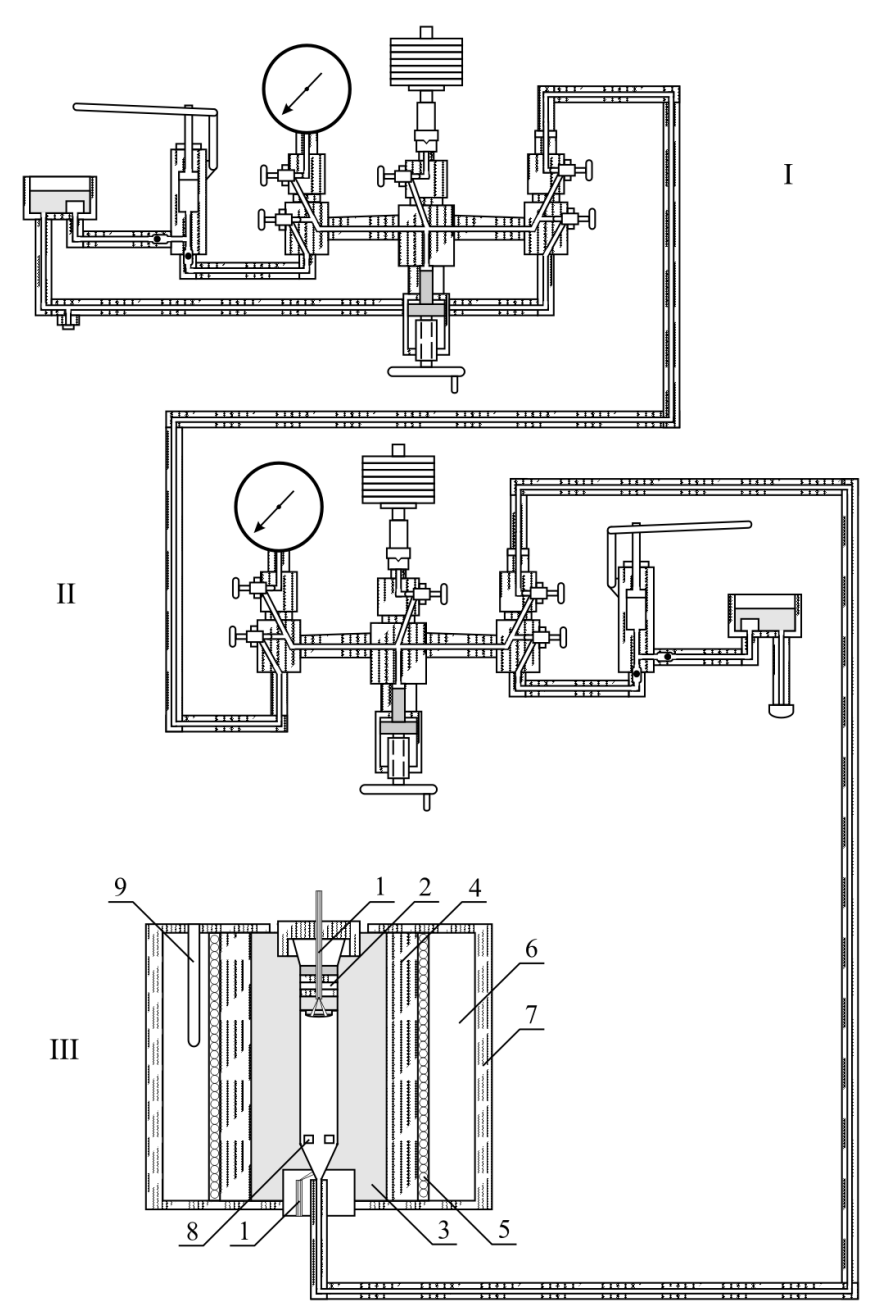

Рис. 1. Блок-схема установки для $P-V-T$ дослідження у рідинних системах: 1 - стержень робочої камери; 2 - система ущільнення; 3 - автоклав високого тиску; 4-зовнішня оболонка автоклаву високого тиску; 5 - обмотка електронагрівача; 6 - скловолокно; 7 - захисна камера; 8 - термометри опору; 9 кювета для термометра

Схему робочої камери для $P-V-T$ вимірів наведено на рис. 2. Сільфон заповнюється досліджуваною рідиною під вакуумом. При підвищенні тиску всередині автоклава змінюється лише довжина сільфона, а поперечний переріз сільфона залишається сталим. Для реєстрації зміни довжини сільфона використовується диференційний трансформаторний датчик лінійних переміщень, що складається з двох зіставлених трансформаторів, які мають спільне рухоме осердя. Висока чутливість датчика досягається завдяки використанню двох вторинних обмоток, які намотані назустріч одна одній. Величина напруги на вторинній обмотці залежить від положення осердя, жорс-

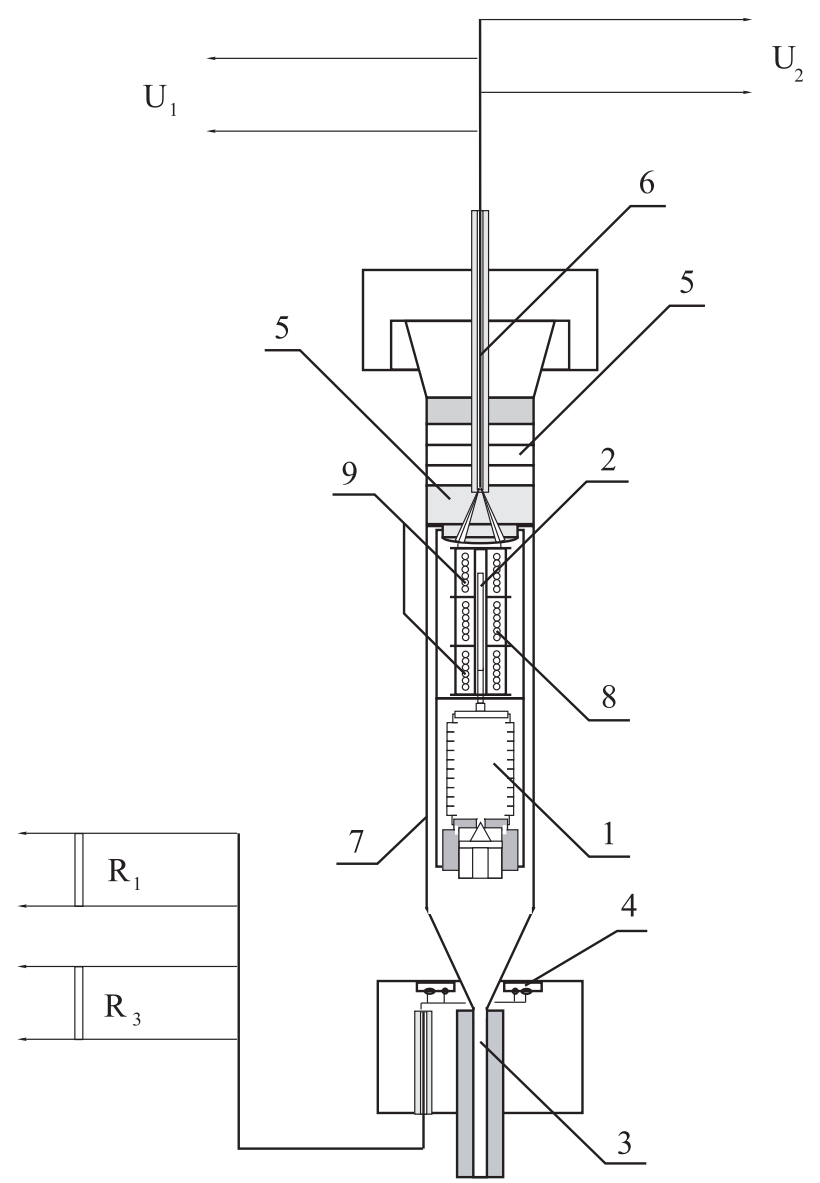

Рис. 2. Схема робочої камери для $P-V-T$ вимірів

тко зв'язаного з робочим сільфоном. Однією з переваг трансформаторного датчика довжини сільфона є наявність значної величини ( 15 мм) лінійної ділянки його характеристики, що відкриває можливість вимірювання досить малих переміщень осердя $(\sim 0,001$ мм), а також незначна величина поправок на температуру і тиск. Такі поправки можуть бути враховані шляхом градуювання датчика довжини. При використанні такої методики за величиною індукованої ЕРС розраховується об'єм сільфона.

\section{3. Результати та їх обговорення}

У табл. 1 подано отримані експериментальні значення густини магнітної рідинної системи вода-магнетитлауринова кислота, які порівняні з аналогічними даними для води, отриманими на цій же установці.

Як бачимо з табл. 1, для досліджуваних температур густина магнітної рідинної системи на основі води при збільшенні тиску зростає значно швидше, ніж 
густина води. Цей факт свідчить про те, що сили відштовхування між молекулами в досліджуваній магнітній рідинній системі менші, ніж у воді.

Використовуючи отримані $P-V-T$ дані ми розрахували ізобаричний коефіцієнт теплового розширення для води та дослідженої магнітної рідинної системи за формулою

$\alpha_{P}=\frac{1}{V}\left(\frac{\partial V}{\partial T}\right)_{P}=-\frac{1}{\rho}\left(\frac{\partial \rho}{\partial T}\right)_{P}$.

Розраховані значення коефіцієнта теплового розширення $\alpha_{P}$ для води та досліджуваної магнітної рідинної системи подано у табл. 2.

Проаналізувавши табл. 1, бачимо, що величина ізобаричного коефіцієнта теплового розширення системи вода-магнетит-лауринова кислота в декілька разів менша за величину ізобаричного коефіцієнта теплового розширення води. Таке зменшення коефіцієнта теплового розширення в досліджуваному інтервалі температур пов'язане зі збільшенням енергії міжмолекулярної взаємодії в системі при додаванні магнетиту, обгорнутого молекулами лауринової кислоти, у воду, за рахунок дії сил притягання між внесеними магнітними частинками.

Отримані експериментальні дані дозволяють розрахувати ізотермічний приріст ентропії за формулою

$T \Delta S=-T \int_{P_{0}}^{P}\left(\frac{\partial V}{\partial T}\right)_{P}$.

Числове інтегрування здійснювалось методом Сімпсона. Ізотермічний приріст ентропії води та системи вода-магнетит-лауринова кислота наведено на рис. 3 .

Порівняння баричних залежностей ізотермічного приросту ентропії у системі вода-магнетитлауринова кислота та воді показує, що зростання тиску значно менше впливає на ізотермічний приріст ентропії в магнітній рідинній системі, ніж у воді. Таким чином, виходячи з отриманих приростів ентропії

Т а б л и ц я 1. Баричні залежності густини $\rho\left(\mathrm{kг} / \mathrm{M}^{3}\right)$ магнітної рідинної системи вода-магнетит-лауринова кислота та води для температур $308,8 \mathrm{~K}$ та $330,2 \mathrm{~K}$

\begin{tabular}{cccccc}
\hline$T, \mathrm{~K}$ & $0,1 \mathrm{MПа}$ & $10,0 \mathrm{MПа}$ & $50,0 \mathrm{MПа}$ & $103,2 \mathrm{MПа}$ \\
\hline \multicolumn{5}{c}{ вода-магнетит-лауринова кислота } \\
$308,8 \mathrm{~K}$ & 2481 & 2511 & 2633 & 2799 \\
$330,2 \mathrm{~K}$ & 2467 & 2498 & 2618 & 2784 \\
& \multicolumn{5}{c}{ вода } \\
$308,8 \mathrm{~K}$ & 993 & 998 & 1014 & 1034 \\
$330,2 \mathrm{~K}$ & 984 & 989 & 1005 & 1025 \\
\hline
\end{tabular}

$\mathrm{T} \Delta \mathrm{S}$, Дж/Кг

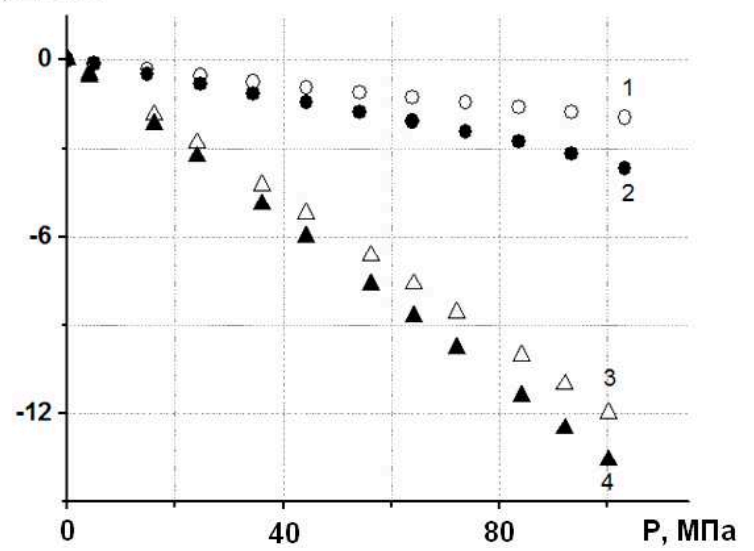

Рис. 3. Баричні залежності ізотермічного приросту ентропії для системи вода-магнетит-лауринова кислота і для води при температурі $308,8 \mathrm{~K}(1,3)$ та $317,4 \mathrm{~K}(2,4)$

і коефіцієнтів теплового розширення, можна зробити висновок, що істотна зміна коефіцієнта теплового розширення при додаванні до води магнетиту, оточеного лауриновою кислотою, пов'язана з дією двох чинників: збільшенням сил міжчастинкової взаємодії і зміною молекулярної структури в досліджуваній рідинній системі у порівнянні зі структурою води.

Отримані експериментально значення густини системи вода-магнетит-лауринова кислота були описані за допомогою напівемпіричного рівняння стану Тейта-Таммана:

$\frac{1}{V_{0}}\left(\frac{\partial V}{\partial P}\right)_{T}=-\frac{A}{B+P}$,

де $A$ і $B$ - сталі рівняння Тейта-Таммана, $V$ - об'єм системи, $V_{0}$ - об'єм системи при атмосферному тиску, $P$ - тиск. У результаті обробки масиву експериментальних даних для води та системи вода-магнетит-

Т а б л и ц я 2. Ізобаричний коефіцієнт теплового розширення $\alpha_{P} \cdot 10^{3}(1 / \mathrm{K})$ магнітної рідинної системи на основі води та води

\begin{tabular}{c|c|c|c|c}
\hline$P$, МПа & $307,0 \mathrm{~K}$ & $308,8 \mathrm{~K}$ & $317,4 \mathrm{~K}$ & $319,3 \mathrm{~K}$ \\
\hline \multicolumn{5}{c}{ вода-магнетит-лауринова кислота } \\
$0,1 \mathrm{MПа}$ & 0,21 & 0,22 & 0,24 & 0,25 \\
$44,3 \mathrm{MПа}$ & 0,19 & 0,20 & 0,27 & 0,29 \\
$63,9 \mathrm{MПа}$ & 0,18 & 0,19 & 0,28 & 0,30 \\
$103,2 \mathrm{MПа}$ & 0,12 & 0,16 & 0,32 & 0,35 \\
& \multicolumn{5}{c}{ вода } \\
$0,1 \mathrm{MПа}$ & 0,26 & 0,36 & 0,41 & 0,49 \\
$44,3 \mathrm{MПа}$ & 0,32 & 0,39 & 0,43 & 0,48 \\
$63,9 \mathrm{MПа}$ & 0,33 & 0,39 & 0,43 & 0,47 \\
$103,2 \mathrm{MПа}$ & 0,35 & 0,40 & 0,43 & 0,47 \\
\hline
\end{tabular}




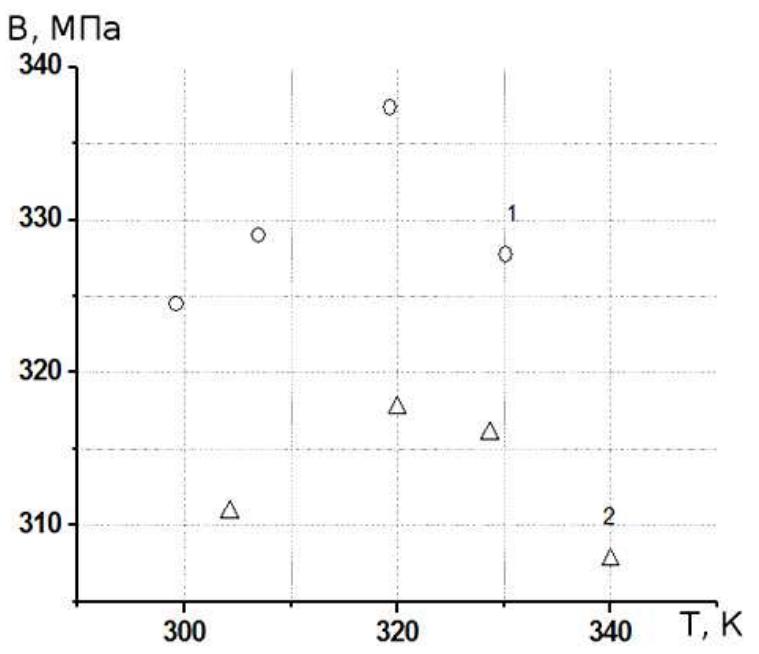

Рис. 4. Стала $B$ рівняння стану Тейта-Таммана для системи вода-магнетит-лауринова кислота (1) та води (2) в дослідженому інтервалі температур

лауринова кислота було знайдено сталі рівняння та проведено їх порівняння. Із статистичного обгрунтування рівняння стану Тейта-Таммана випливає, що величина $B$ у цьому рівнянні пропорційна глибині потенціальної ями ефективного потенціалу міжчастинкової взаємодії, а значення сталої $A$ обернено пропорційне крутизні відштовхувальної гілки цього потенціалу [4]. Як показав експеримент, значення сталої $A$ від температури не залежить, причому для води ця величина становить 0,137 , для системи вода-магнетит-лауринова кислота вона дорівнює 0,420. На відміну від сталої $A$ величина $B$ у цьому рівнянні залежить від температури. На рис. 4 зіставлено температурні залежності коефіцієнта $B$ рівняння стану Тейта-Таммана для системи вода-магнетитлауринова кислота та води. Як випливає з отриманих значень та магнітної рідинної системи, для неї характерні менші значення похідної у відштовхувальній гілці потенціалу та більша глибина ефективного потенціалу міжчастинкової взаємодії порівняно з потенціалом міжчастинкової взаємодії молекул у воді (рис. 5).

\section{4. Висновки}

Таким чином, грунтуючись на отриманих експериментальних $P-V-T$ даних для магнітної рідинної системи вода-магнетит-лауринова кислота та води та обробці їх за допомогою рівняння стану ТейтаТаммана, враховуючи статистичне обгрунтування цього рівняння стану, можна зробити висновок про

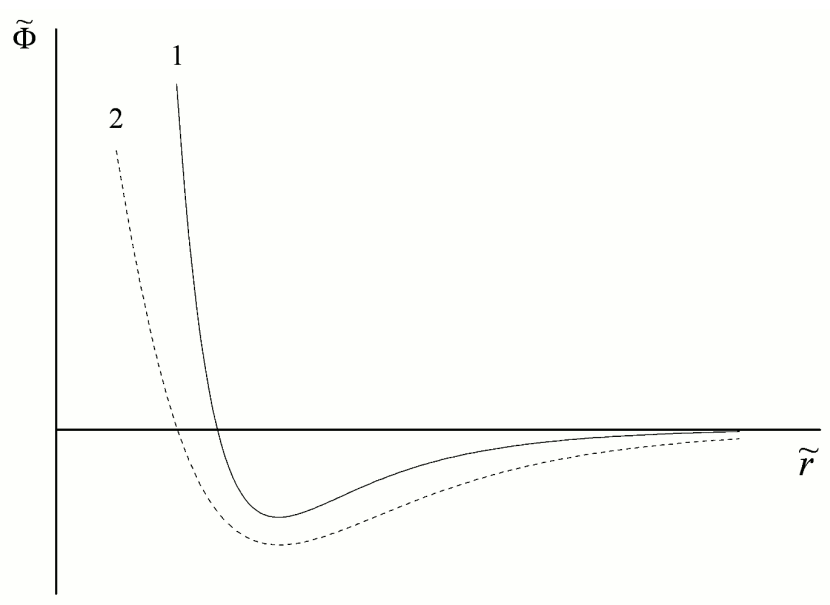

Рис. 5. Ефективний потенціал міжмолекулярної взаємодії молекул $\widetilde{\Phi}(\widetilde{r})$ у воді (1) та в системі вода-магнетит-лауринова кислота (2), де $\widetilde{\Phi}=\Phi /\left(k_{\mathrm{B}} T_{m}\right), \widetilde{r}=r / \sigma_{\mathrm{H}_{2} \mathrm{O}}, k_{\mathrm{B}} T_{\text {пл }}-$ масштаб енергії теплового руху молекул в околі точки плавлення льоду, $\sigma_{\mathrm{H}_{2} \mathrm{O}}-$ ефективний діаметр молекул води

те, що для досліджуваної магнітної рідинної системи порівняно з водою спостерігається зменшення крутизни гілки ефективного потенціалу міжмолекулярної взаємодії, яка відповідає за міжмолекулярне відштовхування. Разом з тим, спостережуване зростання значень величини $B$ у рівнянні стану Тейта-Таммана для системи вода-магнетит-лауринова кислота порівняно з водою свідчить про збільшення глибини потенціальної ями ефективного потенціалу міжчастинкової взаємодії приблизно на 10\%, яке, у свою чергу, викликає зменшення ізобаричного коефіцієнта теплового розширення і зміну молекулярної структури досліджуваної системи у порівнянні з водою. Отже, досліджена магнітна рідинна система вода-магнетитлауринова кислота має істотно менший коефіцієнт теплового розширення порівняно з водою, що пояснюється зміною енергї міжчастинкової взаємодії і перебудовою структури води при додаванні до неї магнітних частинок, покритих лауриновою кислотою.

1. R.E. Rosensweig, Ferrohydrodynamics (Cambridge Univercity Press, Cambridge, 1985).

2. I. Anton, I. De Sabata, and L. Vekas, J. Magn. Magn. Mater. 85, 219 (1990).

3. B. Berkovsky and V. Bashtovoi, Magnetic fluids and applications handbook (Begell House, New York, 1996).

4. І.І. Адаменко, Л.А. Булавін, Фізика рідин та рідинних систем (АСМІ, Київ, 2006).

5. В.И. Петренко, Л.А. Булавин, М.В. Авдеев и др., УФЖ 53, 229 (2008). 
6. Л.А. Булавін, Сучасні проблеми молекулярної фізики (ВПЦ "Київський Університет", Київ, 2006).

7. M.A. Willard, L.K. Kurihara, E.E. Carpenter et al., Inter. Mater. Rev. 49, 125 (2004).

8. G. Baldi, D. Bonacchi, M.C. Franchini et al., Langmuir 7, 4026 (2007).

9. T.R. Pisanic, J.D. Blackwell, V.I. Shubayev et al., Biomaterials 16, 2572 (2007).

10. A.S. Arbab, W. Liu, and J.A. Frank, Expert Rev. Med. Devices 4, 427 (2006).

11. A. Ito, M. Shinkai, H. Honda et al., J. Biosci. Bioeng. 100, 1 (2005).

12. A.K. Gupta and M. Gupta, Biomaterials 26, 3995 (2005).

Одержано 26.04.11

\section{УРАВНЕНИЕ СОСТОЯНИЯ МАГНИТНОЙ \\ ЖИДКОСТНОЙ СИСТЕМЫ НА ОСНОВЕ ВОДЫ, СТАБИЛИЗИРОВАННОЙ ЛАУРИНОВОЙ КИСЛОТОЙ}

\section{Л.А. Булавин, К.А. Мороз, С.П. Недяк, В.И. Петренко}

$\mathrm{P}$ е $з$ ю м е

В данной статье представлены результаты исследования термодинамических свойств магнитной жидкостной системы на основе воды, стабилизированной двойным слоем лауриновой кислоты. Термодинамические свойства исследуемой системы были рассчитаны на основе значений плотности, экспериментально измеренных при разных значениях давления и температуры. Построены, проанализированы и сопоставлены с аналогичными данными для воды барические и температурные зависимости термодинамических свойств исследуемого ферро- флюида. Экспериментальные значения плотности данной системы при разных значениях давления и температуры описаны при помощи полуэмпирического уравнения состояния ТэйтаТаммана. Значения параметров уравнения состояния магнитной жидкостной системы сопоставлены со значениями параметров этого же уравнения состояния для воды и проанализировано влияние добавок на свойства жидкостной системы на основе воды.

\section{THE EQUATION OF STATE FOR A WATER-BASED MAGNETIC FLUID STABILIZED BY LAURIC ACID}

\section{L.A. Bulavin, K.O. Moroz, S.P. Nedyak, V.I. Petrenko}

Taras Shevchenko National University of Kyiv (64, Volodymyrs'ka Str., 01601 Kyiv, Ukraine; e-mail:morozko@univ.kiev.ua,bulavin@univ.kiev.ua, spnedyak@mail.ru)

\section{$\mathrm{S} \mathrm{u} \mathrm{m} \mathrm{m} \mathrm{a} \mathrm{r} \mathrm{y}$}

Thermodynamic properties of a water-based magnetic fluid stabilized by a double layer of lauric acid deposited onto magnetite are calculated on the basis of the values of magnetic fluid density measured experimentally at various pressures and temperatures. The pressure and temperature dependences of the density, isobaric coefficient of thermal expansion, and isothermal increment of entropy of the ferrofluid are plotted, analyzed, and compared with the corresponding data for water. The experimental values obtained for the system concerned are described with the use of the semiempirical Tait-Tamman equation of state. The temperature dependences obtained for the parameters of this equation are analyzed and compared with the analogous dependences for water. 